Richard J. Sinke • Victoria E. H. Carlton · Jenneke A. Juijn · Tammo Delhaas • Laura Bull Gerard P. van Berge Henegouwen · Jan van Hattum • Klaus M. Keller • Maarten Sinaasappel Charles M. A. Bijleveld • Irma E. Knol • Hans-Kristian Ploos van Amstel • Peter L. Pearson • Ruud Berger Nelson B. Freimer • Roderick H. J. Houwen

\title{
Benign recurrent intrahepatic cholestasis (BRIC): evidence of genetic heterogeneity and delimitation of the BRIC locus to a 7-CM interval between D18S69 and D18S64
}

Received: 6 March 1997 / Accepted: 26 March 1997

\begin{abstract}
Benign recurrent intrahepatic cholestasis (BRIC) is an autosomal recessive liver disease characterized by multiple episodes of cholestasis without progression to chronic liver disease. The gene was previously assigned to chromosome $18 \mathrm{q} 21$, using a shared segment analysis in three families from the Netherlands. In the present study we report the linkage analysis of an expanded sample of 14 BRIC families, using 15 microsatellite markers from the $18 \mathrm{q} 21$ region. Obligate recombinants in two families place the gene in a 7-cM interval, between markers D18S69 and D18S64. All intervening markers had sig-
\end{abstract}

R. Sinke · T. Delhaas · R. H. J. Houwen

Department of Pediatric Gastroenterology,

Wilhelmina Childrens Hospital, P.O.Box 18009 ,

3501 CA Utrecht, The Netherlands

Tel.: +31-30-2320911; Fax: +31-30-2334825

V. E. H. Carlton · L. Bull · N. B. Freimer

Neurogenetics Laboratory and Center for Neurobiology

and Psychiatry, Department of Psychiatry,

University of California, San Francisco, California, USA

J. A. Juijn · R. Berger

Laboratory for Metabolic Diseases,

Wilhelmina Children's Hospital, Utrecht, The Netherlands

G. P. van Berge Henegouwen · J. van Hattum

Department of Gastroenterology, University Hospital,

Utrecht, The Netherlands

K. M. Keller

Division of Pediatric Gastroenterology/Hepatology,

Department of Pediatrics, University of Bonn, Bonn, Germany

M. Sinaasappel

Division of Pediatric Gastroenterology, Department of Pediatrics, Sophia Children's Hospital, Rotterdam, The Netherlands

C. M. A. Bijleveld

Division of Pediatric Gastroenterology, Department of Pediatrics, University Hospital, Groningen, The Netherlands

I. E. Knol · H. K. Ploos van Amstel · P. L. Pearson

Department of Human Genetics, University of Utrecht,

Utrecht, The Netherlands nificant LOD scores in two-point linkage analysis. Moreover, we identified one family in which the BRIC gene seems to be unlinked to the $18 \mathrm{q} 21$ region, or that represents incomplete penetrance of the BRIC genotype.

\section{Introduction}

Benign recurrent intrahepatic cholerstasis (BRIC) is a rare autosomal recessive liver disease (De Koning et al. 1995) characterized by intermittent attacks of cholestasis without extrahepatic bile duct obstruction (Summerskil and Walshe 1959; Brenard et al. 1989). Each cholestatic attack starts with rising serum bile acid levels, usually followed by hyperbilirubinemia and overt cholestasis (Bijleveld et al. 1989; Brenard et al. 1989). The attacks vary in duration (weeks to months) and resolve spontaneously. No biochemical abnormalities are found in patients between attacks. The initial episode can occur at any age from infancy to adulthood, although most patients present before the age of 25 years. The frequency of attacks varies from several times a year to less than once per decade (Brenard et al. 1989). Progression to chronic liver disease has not been observed, but cholestatic episodes result in substantial morbidity, including pronounced weight loss and deficiency of fat-soluble vitamins. No established treatment is available, although cholestyramine may alleviate symptoms in some patients. Development of an effective therapy is hampered because the basic defect in BRIC is unknown.

The gene for BRIC was originally mapped to chromosome $18 q 21$ through the identification of a shared chromosomal segment in three distantly related patients from an isolated community in the Netherlands (Houwen et al. 1994). The region shared in these patients extended from D18S363 to D18S55, a genetic distance of more than 20 $\mathrm{cM}$. To facilitate future molecular genetic studies we subsequently started to delimit the region of interest by studying additional BRIC families with a more densly spaced set of markers. We now present an analysis of 14 BRIC families from different ethnic sources with microsatellites selected primarily from the Généthon map, with the addi- 
tion of a few markers from other sources. Based upon this analysis we have refined the localization of the BRIC locus to a 7-cM interval between markers D18S69 and D18S64. We also found that one of the Dutch families studied showed no linkage to the $18 \mathrm{q} 21$ region, indicating genetic heterogeneity in BRIC.

\section{Subjects and methods}

BRIC families

Fourteen families, involving 26 living BRIC patients, were analyzed. Except for BRIC family 1, which has been reported elsewhere (De Koning et al. 1995), the pedigrees of these families are summarized in Fig. 1. Seven of these families have been described previously as case reports: family 2 (De Pagter et al. 1976), family
6 (Bijleveld et al. 1989), family 7 (Van Berge Henegouwen 1974), family 8 (Minuk and Shaffer 1987), families B1 and B3 (Rotthauwe and Rotthauwe 1971) and family B4 (Brenard et al. 1989). The diagnosis of BRIC was considered to be established in a patient whenever two attacks with cholestasis were documented without any signs of extrahepatic bile duct obstruction with complete resolution of all signs of cholestasis in between attacks.

The parents of the patients in families 4 and B4 were second cousins, as were the parents of one of the patients in family 5 (Fig. 1). All families studied had Dutch ancestors, except for families B1 and B3, which are German, and family B4, which is French.

\section{DNA isolation and marker typing}

High molecular weight DNA was extracted from whole blood by the salting-out method as described by Miller et al. (1988). Genotyping of the samples was performed using 15 polymorphic microsatellite markers (Table 1) covering $23 \mathrm{cM}$ of the chromosome
Fig.1 Pedigrees of all benign recurrrent intrahepatic cholestasis (BRIC) families included in this study, with the exception of family BRIC-1, which has been reported by De Koning et al. (1995). Filled circles (female) and squares (male) indicate affected individuals

Table 1 Characteristics of the polymorphic markers used in this study

a 1, Buetow et al. (1994);

2, Dib et al. (1996); 3, Straub et al. (1993); 4, Weber (1993) personal communication
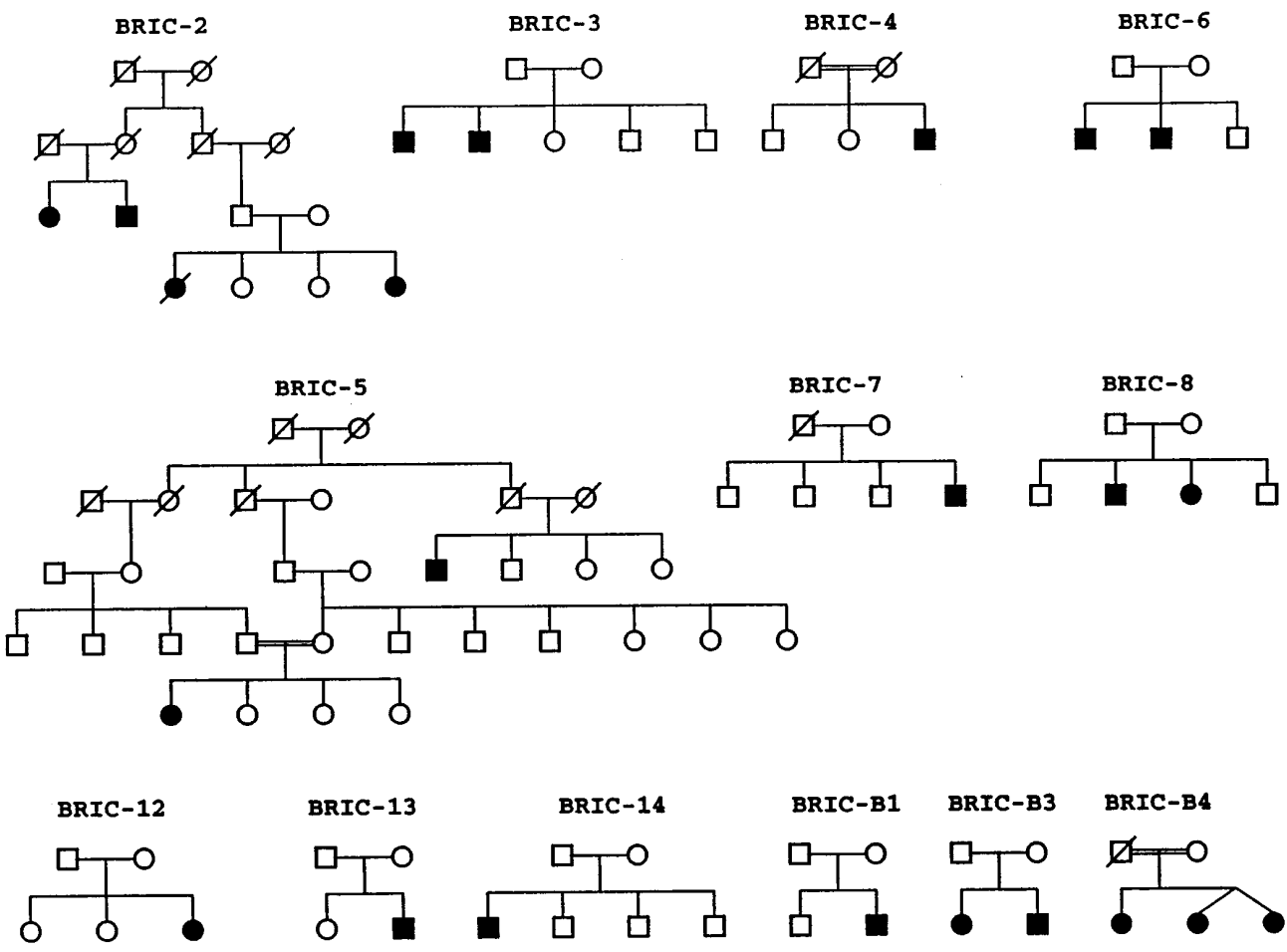

\begin{tabular}{lllll}
\hline Locus & Marker & Heterozygosity & Size range (nucleotides) & Reference $^{\mathrm{a}}$ \\
\hline D18S363 & MFD273 & 0.87 & $177-247$ & 1,4 \\
D18S69 & AFM248yf1 & 0.77 & $194-210$ & 2 \\
D18S39 & MFD193 & 0.77 & $206-230$ & 1,3 \\
D18S41 & CU18-002 & 0.72 & $185-209$ & 1,3 \\
D18S1152 & AFMa054yg5 & 0.79 & $256-274$ & 2 \\
D18S1144 & AFMa043xg1 & 0.85 & $159-181$ & 2 \\
D18S1129 & AFMb317zc1 & 0.84 & $234-258$ & 2 \\
D18S1103 & AFMa239ye9 & 0.85 & $240-254$ & 2 \\
D18S1155 & AFMa065ye9 & 0.65 & $199-209$ & 1,2 \\
D18S64 & AFM212xg5 & 0.73 & $188-208$ & 3 \\
D18S38 & MFD153 & 0.66 & $152-172$ & 2 \\
D18S1147 & AFMa049ze5 & 0.85 & $204-232$ & 1,3 \\
D18S60 & AFM178xe3 & 0.36 & $156-172$ & 2 \\
D18S51 & UT574 & 0.86 & $267-319$ & $134-152$ \\
D18S55 & AFM122XC1 & 0.76 & &
\end{tabular}






Fig. 2 Sex-average map of 15 loci in the BRIC region of chromosome 18. Markers and marker order were derived from Buetow et al. (1994), Dib et al. (1996) and Straub et al. (1993). Genetic distances (in $\mathrm{cM}$ ) are indicated

18q21 region (Fig. 2). Markers were derived from the genetic maps of Généthon (Dib et al. 1996), Straub et al. (1993) and Buetow et al. (1994). Integration of these maps was performed by using the published relative position of those markers that appeared in more than one map (see Table 1). Typically, BRIC families were genotyped by polymerase chain reaction (PCR) amplificaton in an LKB gene ATAQ controller DNA thermal cycler (Pharmacia). The PCRs were carried out in a total volume of $10 \mu \mathrm{l}$ containing $80 \mathrm{ng}$ genomic DNA, 3.2 pmol each primer, $50 \mathrm{mK} \mathrm{KCl}, 10 \mathrm{mM}$ TRIS$\mathrm{HCl}, \mathrm{pH} 8.3,1.5 \mathrm{mM} \mathrm{MgCl}_{2}, 200 \mu \mathrm{M}$ each dATP, dCTP, dGTP and dTTP, $1.5 \mathrm{mg} / \mathrm{ml}$ BSA, $0.15 \mathrm{U}$ Taq DNA polymerase (Perkin Elmer Cetus). PCR conditions were $1 \mathrm{~min} 94^{\circ} \mathrm{C}, 30 \mathrm{~s} 55^{\circ} \mathrm{C}, 30 \mathrm{~s}$ $72^{\circ} \mathrm{C}$ for 30 cycles. The PCR products were analyzed on $6 \%$ polyacrylamide gels containing $8 \mathrm{M}$ urea. As reference for the allele sizes, DNAs from CEPH individuals 1331-1, 1331-2 and 1347-2 or a previously typed BRIC patient were included.

Fig. 3 Haplotypes of the sibships of families 2, 4 and 7 , showing the recombinants localizing the BRIC locus between D18S69 and D18S64 (families 2 and 4 ) and displaying possible nonlinkage (family 7)
Linkage analysis

Pairwise $z$ values between the BRIC locus and each of the markers were calculated with the MLINK option of LINKAGE version 5.2 (Lathrop et al. 1984). The BRIC locus was modelled as an autosomal recessive, two-allele system with complete penetrance. Based on a total of 21 patients identified in the Dutch population (approximately 15 million inhabitants) we used a disease allele frequency of $0.2 \%$. Marker allele frequencies were calculated using the ILINK option of the LINKAGE package from their occurrence in the data set. The ILINK option was also used for the calculation of the maximum lod scores.

\section{Linkage disequilibrium analysis}

Linkage disequilibrium (LD) analysis was carried out using a likelihood ratio test (Terwilliger 1995). This test assumes that in a founder population, such as we believe the Dutch samples are derived from, the marker alleles that were present on the ancestral chromosome in the vicinity of the disease gene will be overrepresented on disease chromosomes, in comparison with normal chromosomes. The test calculates a parameter $\lambda$, which is a measure of this overrepresentation. As it is not known a priori which allele will be associated with the disease, the likelihoods are calculated for all alleles for each $\lambda$. The likelihoods are then weighed according to the population allele frequencies and summed to calculate the total associated likelihood.

This likelihood ratio test was carried out using only Dutch BRIC families and the markers D18S39, D18S41, D18S1152, D18S1144, D18S1129, D18S1155, and D18S1103. These markers are all located in the interval defined by the absence of recombinations in the families described. For this analysis allele frequencies were calculated from the Dutch families and rare alleles were pooled until no allele, or pool of alleles, had a frequency of less than $4 \%$.

\section{Results}

Genotyping of 15 microsatellite markers from the $18 \mathrm{q} 21$ region was conducted in 14 BRIC families. Two crossing over events were detected that define the BRIC critical region (Fig. 3). In family 2 an obligate recombinant between two affected sibs excluded D18S69 and other proximal markers. In family 4 the parents of the patient were second cousins. However homozygosity is only noted for
BRIC-2


0185363 D18S69 D18S39 D18S115 D18S1144 D18S1129 D18S64

D18560

D18S55
BRIC-4

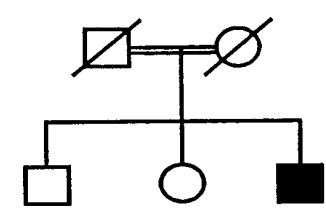

177195 $\begin{array}{llll}198 & 198 & 198 & 204\end{array}$ $\begin{array}{llll}212 & 222 & 212 & 224\end{array}$ 195205 258268 175169 $246 \cdot 252$ 250248 199201 188188 162164 102164 212204 158158 $\begin{array}{ll}287 & 287 \\ 138 & 142\end{array}$ $\begin{array}{ll}195 & 205 \\ 258 & 264\end{array}$ $\begin{array}{ll}258 & 264 \\ 175 & 169\end{array}$ \begin{tabular}{ll|l}
175 & 169 \\
246 & 244
\end{tabular} $\begin{array}{lll}246 & 244\end{array}$ 248246 199199 188192 162162 212204 158158 158158 $\begin{array}{ll}287 & 287 \\ 138 & 142\end{array}$

\begin{tabular}{|ll|}
\hline 195 & 195 \\
198 & 198 \\
222 & 222 \\
205 & 205 \\
268 & 268 \\
169 & 169 \\
252 & 252 \\
250 & 250 \\
201 & 201 \\
\hline 192 & 188 \\
162 & 164 \\
228 & 204 \\
158 & 158 \\
299 & 287 \\
138 & 142 \\
\hline
\end{tabular}

BRIC-7
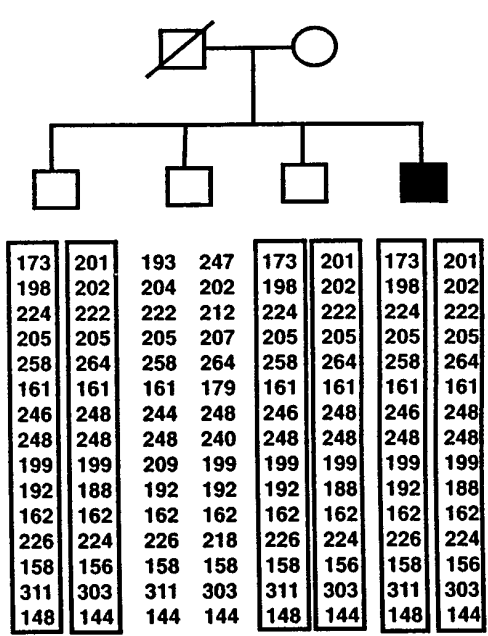
Table 2 LOD scores for polymorphic DNA markers from the BRIC critical region. (MLINK/ILINK generated; families 1a, 1b, 1c, 2, 3, 4, 5, $6,7,8,12,13,14, \mathrm{~B} 1, \mathrm{~B} 3, \mathrm{~B} 4)$

${ }^{a}$ Without family 8

\begin{tabular}{llllllll}
\hline Marker & $\theta=0.000$ & $\theta=0.1$ & $\theta=0.2$ & $\theta=0.3$ & $\theta=0.4$ & $\theta=0.5$ & Maximum LOD score \\
\hline D18S363 & $-\infty$ & 6.520 & 4.312 & 2.292 & 0.802 & 0.000 & 7.592 at $\theta=0.028$ \\
D18S69 & $-\infty$ & 3.572 & 2.153 & 1.033 & 0.325 & 0.000 & 4.451 at $\theta=0.021$ \\
D18S39 & $-\infty$ & 5.047 & 3.430 & 1.892 & 0.682 & 0.000 & 5.904 at $\theta=0.023$ \\
D18S41 & 5.223 & 3.837 & 2.459 & 1.282 & 0.436 & 0.000 & 5.223 at $\theta=0.000$ \\
D18S1152 & 8.638 & 6.153 & 3.845 & 1.953 & 0.654 & 0.000 & 8.638 at $\theta=0.000$ \\
D18S1144 & 7.806 & 5.533 & 3.471 & 1.803 & 0.634 & 0.000 & 7.806 at $\theta=0.000$ \\
D18S1129 & 8.273 & 5.967 & 3.779 & 1.956 & 0.682 & 0.000 & 8.273 at $\theta=0.000$ \\
D18S1103 & 6.946 & 4.921 & 3.031 & 1.493 & 0.470 & 0.000 & 6.946 at $\theta=0.000$ \\
D18S1155 & 6.231 & 4.455 & 2.802 & 1.428 & 0.475 & 0.000 & 6.231 at $\theta=0.000$ \\
D18S64 & 5.958 & 4.919 & 3.266 & 1.778 & 0.644 & 0.000 & 6.042 at $\theta=0.011$ \\
D18S38 & 3.666 & 3.093 & 1.988 & 1.033 & 0.353 & 0.000 & 3.782 at $\theta=0.016$ \\
D18S1147 a & $-\infty$ & 4.200 & 2.802 & 1.491 & 0.528 & 0.000 & 4.754 at $\theta=0.035$ \\
D18S60 $_{\text {D18S51 }}$ & 2.241 & 1.660 & 1.050 & 0.526 & 0.159 & 0.000 & 2.241 at $\theta=0.000$ \\
D18S55 $^{\mathrm{a}}$ & $-\infty$ & 4.661 & 3.256 & 1.830 & 0.680 & 0.000 & 5.183 at $\theta=0.036$ \\
\hline
\end{tabular}

markers centromeric to, but not including, D18S64. Together these recombinants reduce the BRIC region to an interval between D18S64 and D18S69.

Analysis of family 7 revealed that the haplotypes carried by the patient were present in identical form in two older brothers who had never had any attacks of cholestasis (Fig. 3).

Based upon the genotyping data collected in all 14 BRIC families, pairwise lod scores were calculated as shown in Table 2. A significant $z$-value was obtained for almost all markers studied, with a highest LOD score of 8.638 for D18S1152. In the region defined by the two obligate recombinants, maximum LOD scores were obtained at $\theta=0.00$, except for D18S39. This is due to family 7 , which showed nonlinkage in the model used (i.e. complete penetrance), and happened to be extremely informative for this marker and less for others (see Fig. 3).

Subsequently, for the seven markers in the region defined by the recombinants, i.e., D18S39, D18S41, D18S1152, D18S1144, D18S1129, D18S1155, and D18S1103, we investigated whether a nonrandom association of alleles at these loci with the BRIC locus could be found. LD was found only for D18S1129 $\left(\lambda=0.406, \chi^{2}=\right.$ 5.22, $1 d f, P=0.02)$. Accounting for testing multiple markers this LD result is suggestive rather than significant.

\section{Discussion}

The present study, using 15 markers from the $18 \mathrm{q} 21$ region in 14 BRIC families, confirms the initial assignment of the BRIC gene to this region. Moreover, identification of two recombinants considerably reduces the BRIC region to a 7-cM interval between D18S64 and D18S69. Genotyping results in the 14 families studied were also consistent with the marker order derived by the integration of three different genetic maps. The LD found for D18S1129 suggests that the BRIC gene resides in the vicinity of this marker, which will focus the positional cloning effort for the gene involved.
The present study includes one BRIC family that does not show linkage to the $18 \mathrm{q} 21$ region. The affected individual in this family, a classical BRIC patient with the matching biochemical profile, has two older brothers with haplotypes identical to the patient, but with a normal phenotype. The patient, now over 40 years of age, had his first attack more than 20 years ago, while his older brothers show no signs of the disease. As the age of onset between all BRIC sib pairs published (Tygstrup 1960; Kühn 1962; Da Silva and De Brito 1966; Biempica et al. 1967; Rotthauwe and Rotthauwe 1971; Lesser 1973; De Pagter et al. 1976; Leiber et al. 1979; Bijleveld et al. 1989; Lau et al. 1989; De Koning et al. 1995) never differed by more than 10 years, it is unlikely that these older brothers will have an attack in the future. So, clinically, they are genuinely unaffected. An undetected double recombinant as an explanation for the identical haplotypes in the patient and his nonaffected brothers is unlikely, given the very short intermarker distance in this region. A new mutation in this particular patient is unlikely too, but cannot be excluded. Under the assumption of complete penetrance, the only possible alternative explanation would be the existence of a second BRIC locus outside the current region of interest, analogous to a second locus for Progressive Familiar Intrahepatic Cholestasis (PFIC) recently shown to exist outside the $18 \mathrm{q} 21$ region (Strautnieks et al. 1996). However PFIC was known to be clinically heterogeneous to start with (Whittington et al. 1994), while BRIC seems to be fairly homogeneous, with patients only differing slightly in the age at onset and the number and severity of attacks. Thus, athough a second BRIC locus is a straightforward explanation of the present results, nonpenetrance of the disease in the two older brothers also merits consideration as an explanation of the finding of identical haplotypes in affected and nonaffected individuals in the same family.

The BRIC gene was initially localized by studying three distantly related patients (Houwen et al. 1994) through the identification of a conserved haplotype in all of these patients. This shared segment approach was 
based on Lander and Botstein's (1986) suggestion that a gene for a specific disease could be mapped by identifying conserved haplotypes in a distantly related population. It was predicted that this method would require a fairly dense marker map, because it was envisaged that the patients to be used in these kind of studies were separated by many meiotic steps. However, in the study that assigned the BRIC gene to 18q21 (Houwen et al. 1994), the three patients studied were only separated by an average of ten meiotic steps, so only 256 markers were sufficient for the initial genome screen. This demonstrated that shared segment mapping can be used to assign a gene by using only a limited number of markers, whenever a suitable population is available. The same principle has been used for the mapping of other monogenic disorders too, in both humans (Puffenberger et al. 1994; Carlton et al. 1995; Kalaydjieva et al. 1996; Newport et al. 1996) and cattle (Charlier et al. 1996).

Byler disease, a form of PFIC, was mapped to the BRIC region on chromosome $18 \mathrm{q} 21$, by studying two distantly related patients, both descendants of Jacob Byler (Carlton et al. 1995). As these two autosomal recessive cholestatic disorders both map to the same region on chromosome 18 , it can hypothesized that they might be caused by a derangement in the same gene. According to this model, BRIC could be caused by relatively mild mutations leaving some residual function in the resulting protein, while Byler disease could be the result of more severe mutations. The clinical and biochemical features of both diseases suggest that the defect may be found in the primary bile acid secretory pathway. However, thus far, no obvious candidate genes have been mapped to this genomic interval, such as genes belonging to the ABC superfamily known to be involved in many transport processes in the liver (Allikmets et al. 1996). Therefore, further fine mapping of the BRIC and Byler loci, and the assignment of new microsatellite markers to the critical interval are required to facilitate positional cloning of the gene(s) involved. To this end a yeast artificial chromosome contig spanning the critical region has been constructed and will be used as a source for the isolation of new markers and for the identification of canditate genes. Additionally, the search for new BRIC families will be continued to narrow down the region of interest by LD analysis and/or the identification of informative recombinants. Such families will also be useful to investigate the possibility of genetic heterogeneity and/or nonpenetrance in BRIC. The ultimate cloning of the gene(s) involved will help to determine the relationship between BRIC and Byler disease, and may provide important insights into the biology of bile secretion.

Acknowledgements This work was supported by a grant from the Wilhelmina Research Foundation. The authors wish to thank Dr. M. J. T. van Eijk for critical reading of the manuscript and Drs. A. G. F. De Pagter and L. A. Sandkuijl for continuing support. N. B. Freimer was supported by a grant from the National Institutes of Health. V. E. H. Carlton is a recipient of a predoctoral fellowship from the Howard Hughes Medical Institute. Dr. J. Weissenbach (Généthon, Evry, France) is acknowledged for making available the AFM chromosome 18 markers between D18S64 and D18S69.

\section{References}

Allikmets R, Gerrard B, Hutchinson A, Dean M (1996) Characterization of the human ABC superfamily: isolation and mapping of 21 new genes using the Expressed Sequence Tags database. Hum Mol Genet 10: 1649-1655

Biempica L, Gutstein S, Arias IM (1967) Morphological and biochemical studies of benign recurrent cholestasis. Gastroenterology $52: 521-535$

Bijleveld CMA, Vonk RJ, Kuipers F, Havinga R, Fernandes J (1989) Benign recurrent intrahepatic cholestasis: a long term follow-up study of two patients. Hepatology 9:532-537

Brenard R, Geubel AP, Benhamou JP (1989) Benign recurrent intrahepatic cholestasis. A report of 26 cases. J Clin Gastroenterol $11: 546-551$

Buetow KH, Weber JL, Ludwigsen S, Scherpbier-Heddema T, Duyk GM, Sheffield VC, Wang Z, Murray JC (1994) Integrated human genome-wide maps constructed using the $\mathrm{CEPH}$ reference panel. Nat Genet 6:391-393

Carlton VEH, Knisely AS, Freimer NB (1995) Mapping of a locus for progressive familial intrahepatic cholestasis (Byler disease) to $18 \mathrm{q} 21-\mathrm{q} 22$, the benign recurrent intrahepatic cholestasis region. Hum Mol Genet 4 : 1049-1053

Charlier C, Farnir F, Berzi P, Vanmanshoven P, Brouwers B, Vromans H, Georges M (1996) Identity-by-descent mapping of recessive traits in livestock: application to map the bovine syndactyly locus to chromosome 15. Genome Res 6:580-589

Da Silva LC, De Brito T (1966) Benign recurrent intrahepatic cholestasis in two brothers: a clinical, light and electron microscopy study. Ann Intern Med 65:330-341

De Koning TJ, Sandkuijl LA, De Schryver JEAR, Hennekam EAM, Beemer FA, Houwen RHJ (1995) Autosomal recessive inheritance of benign recurrent intrahepatic cholestasis. Am J Med Genet 57:479-482

De Pagter AGF, Van Berge Henegouwen GP, Ten Bokkel Huinink JA, Brandt KH (1976) Familial benign recurrent intrahepatic cholestasis: interrelation with intrahepatic cholestasis of pregnancy and from oral contraceptives? Gastroenterology 71: 202-207

Dib C, Fauré S, Fizames C, Samson D, Drouot N, Vignal A, Millaseau P, Marc S, Hazan J, Seboun E, Lathrop M, Gyapay G, Morisette J, Weissenbach J (1996) A comprehensive genetic map of the human genome based on 5264 microsatellites. Nature 380:152-154

Houwen RHJ, Baharloo S, Blankenship K, Raeymaekers P, Juyn J, Sandkuijl LA, Freimer NB (1994) Genome screening by searching for shared segments: mapping a gene for benign recurrent intrahepatic cholestasis. Nat Genet 8:380-386

Kalaydjieva L, Hallmayer J, Chandler D, Savov A, Nikolova A, Angelicheva D, King RHH, Ishpekova B, Honeyman K, Calafell F, Shmarov A, Petrova J, Turnev I, Hristova A, Moskow M, Stancheva S, Petkova I, Bittles AH, Georgieva V, Middleton L, Thomas PK (1996) Gene mapping in Gypsies identifies a novel demyelating neuropathy on chromosome 8q24. Nat Genet 14:214-217

Kühn HA (1962) Ikterus durch intrahepatische Cholestase bei Brüdern. Acta Hepato-Splen 9:229-245

Lander ES, Botstein D (1986) Mapping complex genetic traits in humans: new methods using a complete RFLP linkage map. Cold Spring Harbor Symp Quant Biol 51 :49-62

Lathrop GM, Lalouel JM, Julier C, Ott J (1984) Strategies for multilocus linkage analysis in humans. Proc Natl Acad Sci USA 81 :3443-3446

Lau JYN, Lok ASF, Lai CL, Wu PC, Lin HJ (1989) Benign recurrent intrahepatic cholestasis in a Chinese girl. J Gastroenterol Hepatol 4:581-583

Leiber DU, Lagenstein I, Grüttner R (1979) Benigne rezidivierende familiäre intrahepatische Cholestase bei eineiigen Zwillingen. Monatschr Kinderheilkd 127:48-51

Lesser PB (1973) Benign familial recurrent intrahepatic cholestasis. Am J Dig Dis 18:259-264 
Miller SA, Dykes DD, Polesky HF (1988) A simple salting out procedure for extracting DNA from human nucleated cells. Nucleic Acids Res 16:1215

Minuk GY, Shaffer EA (1987) Benign recurrent intrahepatic cholestasis. Evidence for an intrinsic abnormality in hepatocyte secretion. Gastroenterology 93:1187-1193

Newport MJ, Huxley CM, Huston S, Hawrylowicz CM, Oostra BA, Williamson R, Levin M (1996) A mutation in the inteferon- $\gamma$-receptor gene and susceptibility to mycobacterial infection. N Engl J Med 335: 1941-1949

Puffenberger EG, Kauffman ER, Bolk S, Matise TC, Washington SS, Angrist M, Weissenbach J, Garver KL, Mascari M, Ladda R, Slaugenhaupt SA, Chakravarti A (1994) Identity by descent and association mapping of a recessive gene for Hirschsprung disease on human chromosome 13q22. Hum Mol Genet 3: $1217-1225$

Rotthauwe HW, Rotthauwe I (1971) Familiäre rekurrierende intrahepatische Cholestase seit dem frühen Kindesalter. Z Kinderheilkd 110:292-316
Straub RE, Speer MC, Luo Y, Rojas K, Overhauser J, Ott J, Gilliam TC (1993) A microsatellite genetic linkage map of human chromosome 18 . Genomics $15: 48-56$

Strautnieks SS, Kagalwalla AF, Tanner MS, Gardiner RM, Thompson RJ (1996) Locus heterogeneity in progressive familial intrahepatic cholestasis. J Med Genet 33:833-836

Summerskil WHJ, Walshe JM (1959) Benign recurrent intrahepatic obstructive jaundice. Lancet ii : $686-690$

Terwilliger JD (1995) A powerful likelihood method for the analysis of linkage disequilibrium between trait loci and one or more polymorphic marker loci. Am J Hum Genet 56:777-787

Tygstrup N (1960) Intermittent possibly familial intrahepatic cholestatic jaundice. Lancet i : 1171-1172

Van Berge Henegouwen GP (1974) Bile acids and cholestasis, Thesis, University of Nijmegen

Whitington PF, Freese DK, Alonso EM, Schwarzenberg SJ, Sharp HL (1994) Clinical and biochemical findings in progressive familial intrahepatic cholestasis. J Pediatr Gastroenterol Nutr 18: 134-141 